It seemed to me clear therefore, either that one and the same poison had not been always at work, or that it had largely modified its method of self-presentation. Such variations of type may be easily explained; but it needs to be met and explained away, or it will continue to be, as it doubtless has been, one great hindrance in the minds of middle-aged men to the reception of newer views. Ther know what croup was, they see what diphtheria is, and, rightly or wrongly, struggle against the conclusion that they are the same disease.

I went on to state in my last letter, and I repeat now, that the principal point of difference in the two chapters of natural history appears to be this-that a case of purely laryngeal diphtheria nowadays would be a unit in a series of cases, the other units of which series differed from itself, whereas a case of old croup had no such immediate surroundings of faucial, glandular, paralytic, and scarlatinoid brethren.

Dr. Johnson is startled at my saying that hardly one-tenth of the deaths from diphtheria are due to suffocation. But there are degrees of directness in suffocation, varying from the six or eight years process of senile bronchitis to one minute and a half in the practice of Professor Calcraft. Even in scarlet fever death is often accelerated by inter. ference with the air-passages. My a firmation was that the acute and direct strangulation, which was the rule in croup, is really exceptional in diphtheria.

Dr. Johnson asks, fairly enough, whether I believe that membranous croup at the present day is ever other than the result of the diphtheritic poison, and if yes, on what grounds. I will not venture to state that it ever is. We are all waiting for the verdict on this point. There will be room for a doubt, however, in my mind till that more inclusive axiom, Omnis diphthera ex diphtheriâ is definitively settled. Believing at present, not dogmatically, but in a feeble way, that we may have diphtheria without a membrane, and a membrane without diphtheria, having seen two bad cases with paralytic sequelæ (cardiac, and ciliary muscle) in which no membrane ever existed, and another, now under treatment, of stomatitis from toothache, with submaxillary abscess, during which a roll of distinctly diphtheritic membrane formed under the tongue, beside the frænum, without a scintilla of evidence, except the membrane, that any specific poison was at work, I venture provisionally to think that the truih may possibly one day define itself thus:-

1. That a mucous or cutaneous surface may sometimes effuse membranous material under non-specific excitation.

2. That some special excitants, telluric or atmospheric, possess the power and habit of arousing this exudative faculty in special regions, the product being still nonspecific.

3. That the false membrane may appear as a feature and consequence of specific blood-poisoning, when it becomes, of course, itself specific and poison-bearing.

As an illustration, not exaet but suggestive, may be cited the exudation of herpes, sometimes neither specific nor specially localised, as from teething; sometimes specially localised but not specific, as in shingles and after influenza. sometimes associated with and bearing a specific contagion, as in herpes circinatus. Erysipelas might supply even truer exemplications if studied with that view.

Dr. Johnson must forgive me for airing these fantastic ideas side by side with his more solid conclusions. Perhaps he will also pardon one more intrusive suggestion: if in due time he should establish his position and show all these cases to be the result of one and the same poison, surely he will withdraw the nomenclature now proposed. If membranous laryngitis is diphtheria, why not call it so? Stridor is but a feeble link wherewith to join it to essentially different conditions. The profession is only wedded to the word croup because of the happy way in which its vagueness coincides with the vagueness of the pathology which gave it birth. Precision of idea will soon not only permit but demand fitting expression. Suppose three children in one family smitten with diphtheria, should we class the case of the one who died acutely strangled as ¿ congener of laryngismus stridulus under the bead of croup because the child crowed; and the case of the second, under the adynamia, because it ended by exhaustion; and the third as a neurosis, because fatal through paralysis of the heart? Even membranous laryngitis would not do any more than phagedonic tonsillitis would do for some cases of scarlet fever. Dr. Johnson has long had the real matter before him, and no man is more likely to work it thoroughly out. If he can satisfy the world that all these eventualities are varieties of one given disease, diphtheria, and the product of one definite poison, let the whole be called by one name; let the nomenclature follow the facts.

By all means specialise by qualifying adjuncts if required, as laryngeal diphtheria, diphtheric paralysis, \&c., but always include the name which indicates what the condition essen. tially is, and suppress those which indicate affinities whieh it essentially has not. Membranous laryngitis, as suggested by yourself, Sir, and Dr. Johnson, would but little affect the general pathologic idea; it would bespeak no caution against infection, nor invite any other treatment from the routine practitioner than such as he had habitually en. ployed for "inflammatory croup."

Asking you to permit this one more intrusion, I am, Sir, yours faithfully,

Maidstone, Feb. 19th, 1875 . STEPHEN MONCKTON.

\section{BIRMINGHAM MEDICAL INSTITUTE.}

\section{To the Editor of THH LaNcer.}

SIR,-Whether homœopaths shall be admitted as members of the Medical Institute recently formed in this town, is a question of such vast importance to the medical profession that I feel no hesitation in submitting these few remarks on the subject to the notice of your readers.

It appears to me that the whole thing lies in a nutshell. Homoopathic practitioners, or professors, or whatever they they are called (and it matters little whether their system is sound or unsound), have gained admission into the ranks of a profession the principles and practices of which they altogether disapprove, and having secured their degree or diploma from one or other of our own colleges, on the faith of doctrines known as allopathic or, in other words, having obtained a licence to practise in accordance with the principles of "allopathy," they forthwith discard the very system they were admitted to practise, and embrace an entirely new one, the benefits of which to the public are as infinitesimal as the globules they profess to use. This new system bas laboured hard, and is still labouring hard, to upset and destroy the legitimate system of medical practice on which they have so improperly entered, and with which they are now seeking to become more intimately identified.

It will be in the recollection of many of your readers that Dr. Newman, and other ministers of the Church of England were admitted into the clerical profession as homœopaths were admitted into the medical-viz., through the same portals as the legitimate members of those professions; but Dr. Newman feeling a conviction in his mind that the doctrines of the Church of Rome were the sound and true doctrines-and there have been many similar converts to the Church of England,-honestly and honourably seceded from the Church of England. But, Sir, how have the homoepaths acted? Have they honestly and honourably seceded from a profession of which they disapprove? If they are possessed of those honest and honourable feelings, how can they remain members of a profession with the principles and doctrines of which they utterly disagree? Surely such men have no right to expect to be recognised by the legitimate members of the medical profession, and if so, surely they can have no claim to be admitted as members of a society which was founded for the establishment of a medical library and for the dissemination of the principles and practices of allopathy. It is idle for the local preas, or rather for a portion of it, to write such nonsense about depletion, mercurialisation, \&c. The medical profession is far above such petty sneers. A profession which at the present moment is dispensing its gratuitous advice and assistance, entirely without fee or reward, to one-third of the population of this kingdom, may well afford to hold in contempt the sneers and the taunts of another profession which gives not one jot of its professional earnings to this or any other benevolent object.

I am, Sir, yours, \&c.,

Edwin Chesshire, F.R.C.S.

Newhall-street, Hrmingham, Marci 8th, 1875 . 